\title{
Promosi Kesehatan Mengenai Hipertensi Dan Pemeriksaan Laboratorium Di Kelurahan Sumur Dewa Kota Bengkulu
}

\author{
Dessy Triana $^{1}$, Hardiansyah ${ }^{2}$ \\ ${ }^{12}$ Fakultas Kedokteran dan Ilmu Kesehatan Universitas Bengkulu \\ Email :dessy.triana@unib.ac.id
}

Article History:

Received: November 2020

Revised: Juni 2021

Accepted: Juni 2021

Available online: Juni 2021

\section{Kata Kunci: \\ diabetes mellitus, hipertensi, hiperurisemia, hiperkolesterolemia, pemeriksaan kesehatan}

\begin{abstract}
Abstrak:
Hipertensi merupakan salah satu penyakit kardiovaskuler yang paling umum dan banyak diderita oleh masyarakat. Individu dengan hipertensi memiliki risiko lebih tinggi terkena serangan jantung dan stroke, penyakit yang menjadi penyebab kematian nomor satu di dunia setiap tahun. Kegiatan ini bertujuan untuk meningkatkan pengetahuan tentang hipertensi dan komplikasinya serta mengetahui hasil pemeriksaan tekanan darah, glukosa darah, kolesterol dan asam urat sebagai indikator awal dalam pengendalian penyakit degeneratif seperti hipertensi dan komplikasinya. Sosialisasi ini meliputi konsultasi, metode pendidikan dan pemeriksaan laboratorium. Kegiatan ini diikuti oleh 38 warga di RT 29 Kelurahan Sumur Dewa Kota Bengkulu. Hasil dari kegiatan ini dapat digunakan sebagai skrining awal penyakit degeneratif seperti hipertensi dan komplikasinya. Hasil penelitian menunjukkan bahwa hipertensi, hiperkolesterolemia, diabetes mellitus dan hiperurisemia masing-masing sebesar 50\%, $47,37 \%, \quad 15,79 \%, \quad 23,68 \%$. Klasifikasi berdasarkan risiko adalah risiko tinggi, risiko sedang dan risiko rendah masing-masing sebesar $13,16 \%, 42,10 \%, 44,74 \%$. Pemberian edukasi meningkatkan tingkat pengetahuan terkait hipertensi dan komplikasinya.
\end{abstract}




\section{Pendahuluan}

Hipertensi atau yang lebih dikenal dengan nama penyakit darah tinggi merupakan suatu kondisi seseorang yang memiliki tekanan darah di atas ambang batas normal yaitu, tekanan darah sistolik $\geq 140 \mathrm{mmHg}$ dan diastolik $\geq 90 \mathrm{mmHg}$ (Kementerian Kesehatan RI 2020). Pola penyakit di Indonesia mengalami transisi epidemiologi selama dua dekade terakhir, yakni dari penyakit menular yang semula menjadi beban utama kemudian mulai beralih menjadi penyakit tidak menular.. Penyakit tidak menular yang utama di antaranya hipertensi, diabetes melitus, kanker, dan penyakit paru obstruktif kronik (Kementerian Kesehatan RI 2015).

Penderita hipertensi seringkali tidak mengetahui bahwa dirinya menyandang hipertensi, dan baru diketahui setelah terjadi komplikasi dan kerusakan organ. Oleh karena itu, penyakit ini disebut sebagai the silent killer, karena sering tanpa keluhan. Penyakit ini merupakan salah satu pintu masuk atau faktor risiko berbagai penyakit seperti jantung, gagal ginjal, diabetes melitus (DM), dan stroke (American Diabetes Association , 2015).

Penyakit hipertensi dapat meningkatkan risiko terjadinya penyakit kardiovaskular. Setiap peningkatan $20 \mathrm{mmHg}$ tekanan darah sistolik atau 10 mmHg tekanan darah diastolik dapat meningkatkan risiko kematian akibat penyakit jantung iskemik dan stroke (Chobanian et al. 2003). Menjalankan pola hidup sehat setidaknya selama $4-6$ bulan terbukti dapat menurunkan tekanan darah dan secara umum dapat menurunkan risiko permasalahan kardiovaskular. Beberapa pola hidup sehat yang dianjurkan di antaranya penurunan berat badan, mengurangi asupan garam, olahraga, mengurangi konsumsi alkohol, dan berhenti merokok (Saseen and Maclaughlin 2017).

Munculnya masalah kesehatan tidak hanya disebabkan oleh kelalaian individu, namun dapat pula disebabkan oleh ketidaktahuan masyarakat sebagai akibat dari kurangnya informasi yang benar mengenai suatu penyakit (Rahmadiana 2012). Rendahnya pengetahuan tenaga kesehatan, pasien, dan masyarakat tentang hipertensi merupakan penyebab utama tidak terkontrolnya tekanan darah, terutama pada pasien hipertensi di Asia (Park, Kario, and Wang 2015). Hal-hal yang dapat dilakukan sebagai upaya perbaikan kesehatan bukan sekadar memperbaiki kerusakan atau kelainan fisik, tetapi melibatkan kompleksitas kebutuhan, motivasi, dan prioritas individu yang dapat dilakukan melalui komunikasi intrapersonal yang melibatkan jiwa, kemauan, kesadaran, dan pikiran. Masih kurangnya informasi mengenai perbaikan pola 
makan bagi penderita hipertensi juga membuat pengetahuan masyarakat tentang perbaikan pola makan masih rendah (Arianto 2013).

Komunikasi merupakan pengalihan suatu pesan/informasi dari sumber ke penerima yang disampaikan dengan sebaik-baiknya agar dapat dipahami dengan baik. Komunikasi kesehatan diperlukan, terutama untuk menyampaikan pesan dan pengambilan keputusan yang dapat berpengaruh pada pengelolaan kesehatan dengan cara memberikan informasi, menciptakan kesadaran, mengubah sikap, dan memberikan motivasi kepada masyarakat untuk menjalankan pola hidup sehat. Pemberian informasi kesehatan diharapkan dapat mencegah dan mengurangi angka kejadian suatu penyakit dan sebagai sarana promosi kesehatan (Rahmadiana 2012).

Berdasarkan hal tersebut, pengabdian ini bertujuan untuk meningkatkan pengetahuan dan kepedulian tentang penyakit hipertensi dan komplikasinya serta monitoring dan skrining awal penyakit degeneratif seperti hipertensi beserta komplikasinya.

\section{Metode}

Metode kegiatan pengabdian ini memberikan edukasi dan konsultasi mengenai pentingnya pencegahan dan pengendalian hipertensi dan komplikasinya dengan meningkatkan self awareness serta perilaku patuh dalam pengobatan. Kegiatan dilanjutkan dengan pemeriksaan tekanan darah, gula darah, kadar kolesterol dan kadar asam urat di dalam darah untuk melakukan monitoring guna mencegah terjadinya komplikasi penyakit.

\section{Hasil}

Kegiatan pengabdian telah diselenggarakan pada hari minggu tanggal 09 Februri 2020 di Aula Masjid Al Mushawwir RT. 29 Kelurahan Sumur Dewa Kota Bengkulu. Kegiatan sosialisasi ini diikuti sebanyak 38 peserta yang berasal dari RT. 29 Kelurahan Sumur Dewa Kota Bengkulu. Kegiatan ini dilaksanakan selama 4 jam yaitu dari pukul 08.00 sampai dengan 12.00 WIB. Peserta kegiatan sosialisasi ini sebanyak 38 orang dengan rincian pada tabel 1 .

Semua peserta dilakukan pemeriksaan tekanan darah dengan menggunakan spigmomanometer dan pemeriksaan darah untuk mengukur kadar glukosa, kolesterol dan asam urat dengan metode Point of Care Testing (POCT) dengan mengunakan darah kapiler. Hasil pemeriksaan didapatkan sebanyak 50\% menderita hipertensi, $47.37 \%$ hiperkolesterolemia, $15.79 \%$ 
diabetes melitus, $23.68 \%$ hiperurisemia (Gambar 1).

Tabel 1. Peserta Kegiatan Sosialisasi

\begin{tabular}{|c|c|c|c|c|}
\hline No & Nama (inisial) & Umur (tahun) & Jenis Kelamin & Pekerjaan \\
\hline 1 & RU & 43 & $\mathrm{~L}$ & PNS \\
\hline 2 & MA & 65 & $\mathrm{~L}$ & Pensiunan \\
\hline 3 & MF & 48 & $\mathrm{~L}$ & PNS \\
\hline 4 & BH & 39 & $\mathrm{~L}$ & PNS \\
\hline 5 & MY & 50 & $\mathrm{~L}$ & Swasta \\
\hline 6 & ST & 48 & $\mathrm{~L}$ & Swasta \\
\hline 7 & HS & 30 & $\mathrm{~L}$ & Swasta \\
\hline 8 & PA & 43 & $\mathrm{~L}$ & PNS \\
\hline 9 & EZ & 36 & $\mathrm{~L}$ & Swasta \\
\hline 10 & SL & 40 & $\mathrm{~L}$ & POLRI \\
\hline 11 & SM & 39 & $\mathrm{~L}$ & Swasta \\
\hline 12 & DI & 39 & $\mathrm{~L}$ & PNS \\
\hline 13 & FT & 35 & $\mathrm{~L}$ & PNS \\
\hline 14 & IR & 64 & $\mathrm{P}$ & IRT \\
\hline 15 & $\mathrm{TF}$ & 34 & $\mathrm{~L}$ & Swasta \\
\hline 16 & IK & 35 & $\mathrm{~L}$ & Swasta \\
\hline 17 & IS & 39 & $\mathrm{P}$ & BUMN \\
\hline 18 & $\mathrm{JN}$ & 36 & $\mathrm{~L}$ & Swasta \\
\hline 19 & PA & 40 & $\mathrm{~L}$ & Swasta \\
\hline 20 & ED & 50 & $\mathrm{~L}$ & Dosen \\
\hline 21 & $\mathrm{RH}$ & 47 & $\mathrm{~L}$ & POLRI \\
\hline 22 & $\mathrm{HN}$ & 36 & $\mathrm{~L}$ & PNS \\
\hline 23 & FA & 39 & $\mathrm{P}$ & IRT \\
\hline 24 & YF & 42 & $\mathrm{P}$ & PNS \\
\hline 25 & ES & 34 & $P$ & IRT \\
\hline 26 & OL & 59 & $\mathrm{~L}$ & Pensiunan \\
\hline 27 & HW & 52 & $\mathrm{~L}$ & PNS \\
\hline 28 & OY & 65 & $\mathrm{~L}$ & Swasta \\
\hline 29 & DJ & 40 & $\mathrm{~L}$ & POLRI \\
\hline 30 & BY & 31 & $\mathrm{~L}$ & PNS \\
\hline 31 & JK & 31 & $\mathrm{~L}$ & Swasta \\
\hline 32 & MM & 19 & $\mathrm{~L}$ & Mahasiswa \\
\hline 33 & RS & 31 & $\mathrm{P}$ & PNS \\
\hline 34 & PT & 64 & $\mathrm{~L}$ & Swasta \\
\hline 35 & HA & 35 & $\mathrm{P}$ & PNS \\
\hline 36 & $\mathrm{HL}$ & 42 & $\mathrm{P}$ & PNS \\
\hline 37 & SY & 50 & $P$ & IRT \\
\hline 38 & IO & 49 & $\mathrm{P}$ & IRT \\
\hline
\end{tabular}




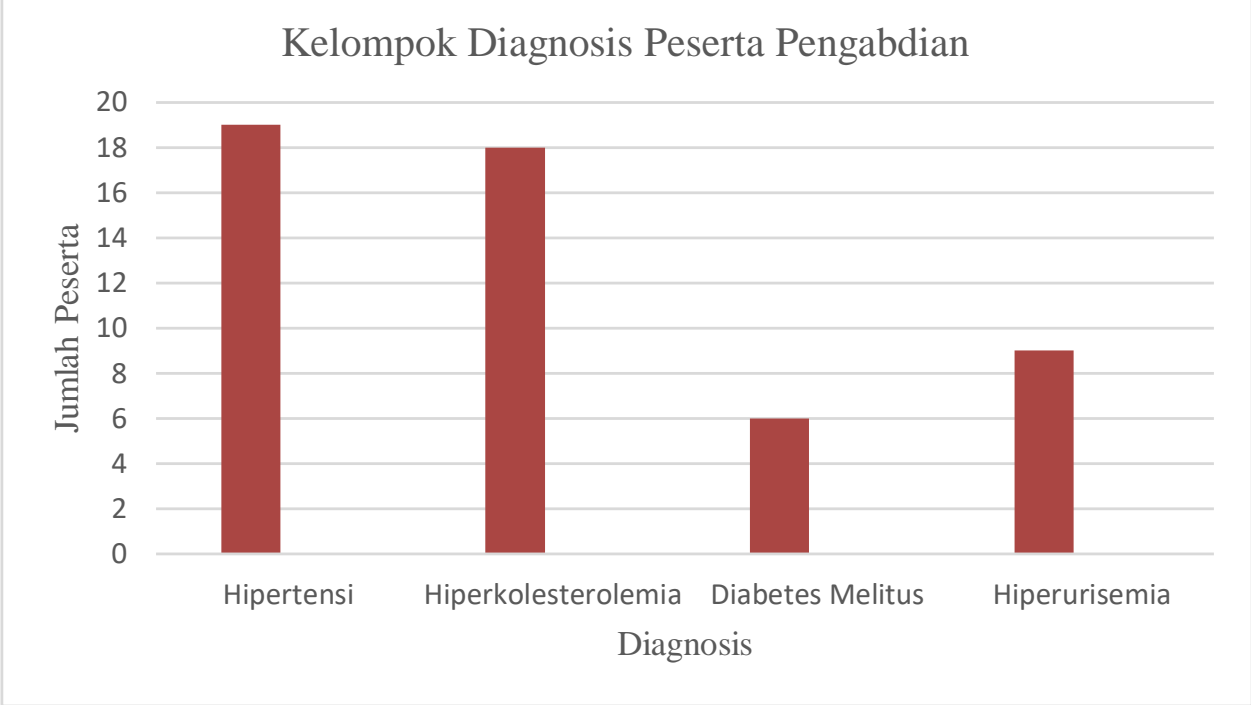

\section{Gambar 1. Pengelompokkan Peserta Berdasarkan Diagnosis}

Hasil dari pemeriksaan ini dilakukan edukasi secara personal kepada peserta sesuai dengan hasil yang didapatkan, untuk peserta dengan kategori risiko rendah (44.74\%) di sarankan untuk tetap mempertahankan pola hidup sehat, makan makanan bergizi dan olahraga rutin. Bagi peserta dengan risiko sedang (42.10\%) dan risiko tinggi (13.16\%) dianjurkan untuk pemeriksaan kesehatan lebih lanjut ke dokter keluarga masing-masing untuk mendapatkan pelayanan kesehatan dan pengobatan serta edukasi untuk patuh dalam pengobatan (Gambar 1).

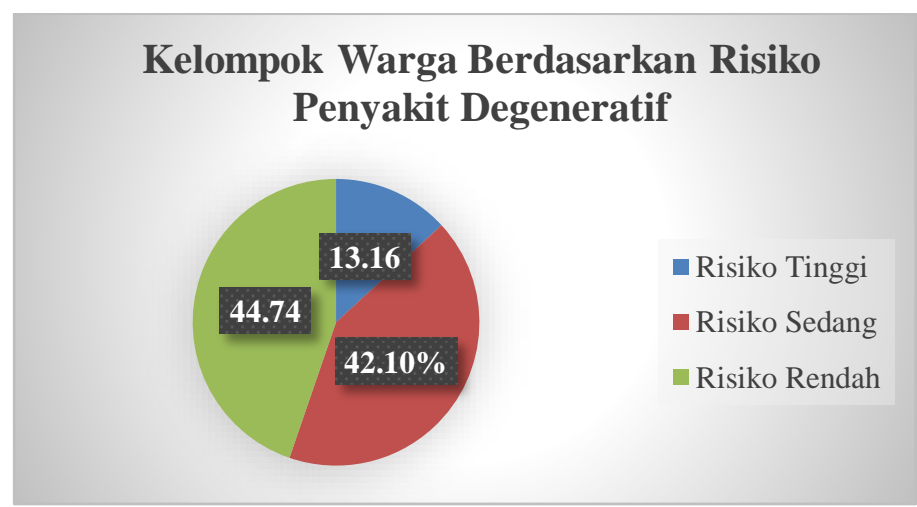

Gambar 2. Pengelompokkan Peserta Kegiatan Berdasarkan Risiko Penyakit Degeneratif 
Kegiatan Sosialisasi Hipertensi dan Pemeriksaan Laboratorium dilakukan di RT. 29 Kelurahan Sumur Dewa Kota Bengkulu. Kegiatan ini melibatkan 2 orang tim pengabdian untuk melakukan pemeriksaan kesehatan. Berikut adalah foto-foto kegiatan sosialisasi:

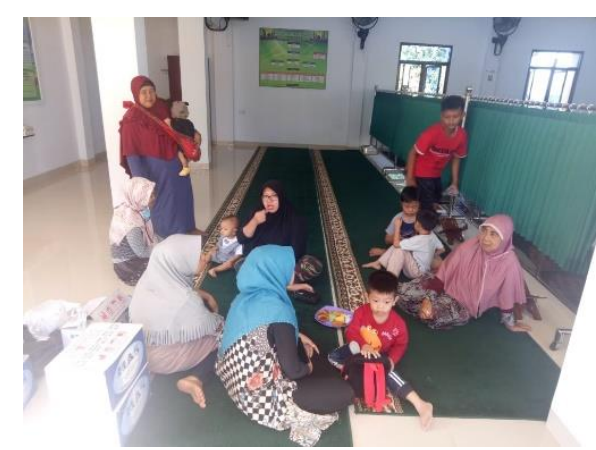

A. Penyuluhan tentang hipertensi

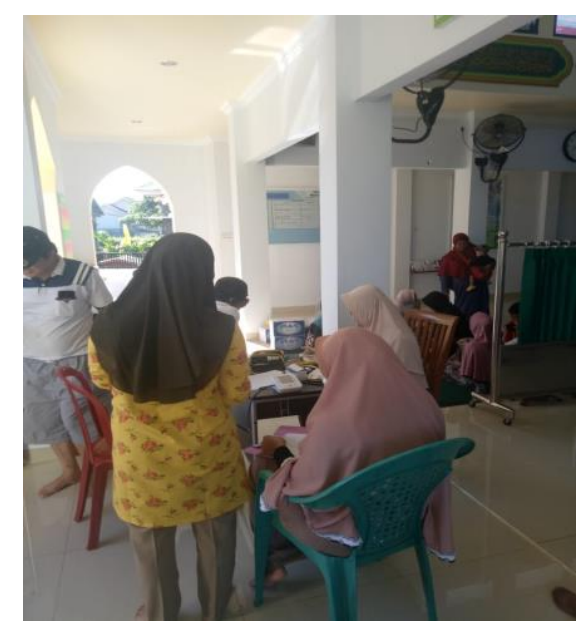

C. Proses pendaftaran peserta

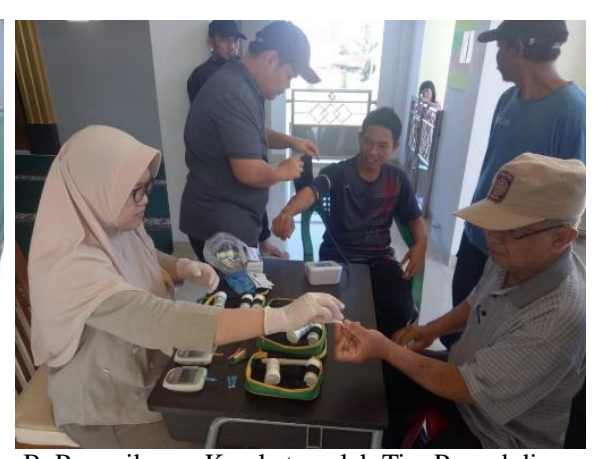

B. Pemeriksaan Kesehatan oleh Tim Pengabdian

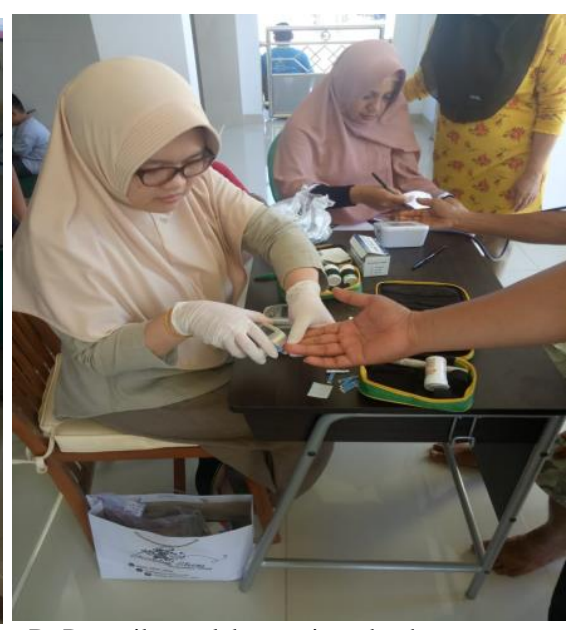

D. Pemeriksaan laboratorium darah

Gambar 3. Kegiatan Sosialisasi Hipertensi dan Pemeriksaan Laboratorium di RT. 29 Kelurahan Sumur Dewa Kota Bengkulu

\section{Hasil}

Promosi kesehatan yang dilakukan adalah dengan metode penyuluhan tentang hipertensi dan faktor risiko terjadinya hipertensi. Penyuluhan ini bertujuan memberikan pengetahuan mengenai hipertensi kepada masyarakat supaya masyarakat dapat melakukan upaya pencegahan penyakit hipertensi. 
Informasi yang didapatkan dari penyuluhan dapat memberikan pengaruh jangka pendek sehingga dapat menghasilkan perubahan atau peningkatan pengetahuan (Widianingrum and Dewi 2013). Dilanjutkan dengan pemeriksaan laboratorium sebagai skrining awal kesehatan dan monitoring kesehatan selanjutnya dapat dilakukan secara berkala. Semakin meningkatnya pengetahuan pasien tentang hipertensi akan mendorong seseorang untuk berperilaku yang lebih baik dalam mengontrol hipertensi sehingga tekanan darahnya tetap terkendali, pengetahuan pasien mengenai hipertensi juga berpengaruh pada kepatuhan pasien dalam melakukan pengobatan. Seiring dengan meningkatnya pengetahuan tentang hipertensi maka dapat melakukan penatalaksanaan penyakitnya sehingga pasien menjadi lebih baik (Wulansari, Ichsan, and Usdiana 2013). Pengetahuan yang baik tentang hipertensi dapat mempengaruhi perilaku masyarakat dalam mencegah hipertensi (Limbong, Rumayar, and Kandou 2016).

Peningkatan pengetahuan pada subjek pemberdayaan diharapkan dapat mendorong peningkatan kesadaran akan pentingnya pencegahan atau deteksi dini hipertensi, penyebab hipertensi, dan bahayanya. Peningkatan kesadaran diharapkan sebagai pemicu perbaikan pola hidup yang selanjutnya mengarah kepada perbaikan tekanan darah. Monitoring yang rutin, warga RT. 29 Kelurahan Sumur Dewa menjadi sering memantau tekanan darah dan menjaga pola hidup untuk mencapai perbaikan tekanan darah.

\section{Kesimpulan}

Jumlah warga yang menderita hipertensi masih tinggi yaitu sebanyak 50\%, diabetes melitus sebanyak $15.79 \%$ hiperkolesterolemia sebanyak $47.37 \%$ dan hiperurisemia sebanyak $23.68 \%$. Hasil pengelompokkan warga berdasarkan risiko didapatkan hasil risiko tinggi sebesar $13.16 \%$, risiko sedang sebesar $42.10 \%$ dan risiko rendah sebesar $44.74 \%$. Monitoring berkala sangat diperlukan untuk mencegah komplikasi penyakit degeneratif lainnya. Edukasi berkelanjutan harus senantiasa dilakukan untuk menjaga kepatuhan dalam pengobatan maupun mempertahankan pola hidup sehat.

\section{Daftar Referensi}

Arianto. 2013. "Komunikasi Kesehatan.” Jurnal Ilmu Komunikasi 3(2):1-13. Association, American Diabetes. 2015. "Standards of Medical Care in Diabetes-2015 Abridged for Primary Care Providers." Clinical Diabetes 33(2):97-111. 
Chobanian, Aram V., George L. Bakris, Henry R. Black, William C. Cushman, Lee A. Green, Joseph L. Izzo, Daniel W. Jones, Barry J. Materson, Suzanne Oparil, Jackson T. Wright, and Edward J. Roccella. 2003. "The Seventh Report of the Joint National Committee on Prevention, Detection, Evaluation, and Treatment of High Blood Pressure: The JNC 7 Report." Journal of the American Medical Association 289(19):2560-72.

Kementerian Kesehatan RI. 2015. Rencana Strategis Kementerian Kesehatan Republik Indonesia Tahun 2015-2019. Jakarta: Kementerian Kesehatan RI, Desember 2015.

Kementerian Kesehatan RI. 2020. "Hipertensi Penyakit Paling Banyak Diidap

Masyarakat.”. Jakarta: Kementerian Kesehatan RI, Agustus 2020.

Limbong, Valdano, Adisti Rumayar, and Grace Kandou. 2016. "Hubungan

Pengetahuan Dan Sikap Dengan Kejadian Hipertensi Di Wilayah Kerja

Puskesmas Tateli Kabupatan Minahasa." Kesmas 7(4):1-5.

Park, Jeong Bae, Kazuomi Kario, and Ji Guang Wang. 2015. "Systolic Hypertension: An Increasing Clinical Challenge in Asia." Hypertension Research 38(4):227-36.

Rahmadiana, Metta. 2012. "Komunikasi Kesehatan: Sebuah Tinjauan." Jurnal Psikogenesis 1(1):88-94.

Saseen, Joseph and Eric J. Maclaughlin. 2017. "Hypertension Pharmacotherapy: A Pathophysiologic Approach." Pp. 131-35 in

Pharmacotherapy: A Pathophysiologic Approach. McGraw-Hill Medical Education.

Widianingrum, Rifka and Hema Dewi. 2013. "Efektifitas Penyuluhan Tentang Hipertensi Pada Masyarakat Rentang Usia 45-60 Tahun Dibandingkan Dengan Masyarakat Rentang Usia 61-75 Tahun The Effectiveness of Counceling of Hypertension In The Age Range Of 45-60 Year Compared With 61-75 Year Age Range Di." Jurnal Kedokteran Muhammadiyah $1(2): 86-92$.

Wulansari, Jayanti, Burhannudin Ichsan, and Devi Usdiana. 2013. "Hubungan Pengetahuan Tentang Hipertesi Dengan Pengendaalian Tekanan Darah Pada Pasien Hipertensi Di Poliklinik.” Biomedika 5(1):17-22. 